\title{
Aminoacyl-tRNA synthetase interacting multi-functional protein 1 attenuates liver fibrosis by inhibiting TGFß signaling
}

\author{
JONGCHAN AHN ${ }^{1 *}$, MI KWON SON ${ }^{2 *}$, KYUNG HEE JUNG ${ }^{2}$, KWANGIL KIM ${ }^{3}$, \\ GI JIN KIM ${ }^{1}$, SOO-HONG LEE ${ }^{1}$, SOON-SUN HONG ${ }^{2}$ and SANG GYU PARK ${ }^{4}$ \\ ${ }^{1}$ Department of Biomedical Science, College of Life Science, CHA University, Gyunggido; \\ ${ }^{2}$ Department of Biomedical Sciences, College of Medicine, Inha University, Incheon; ${ }^{3}$ Department \\ of Pathology, Bundang CHA General Hospital, CHA University, Gyunggido; ${ }^{4}$ Department of \\ Pharmacy, College of Pharmacy, Ajou University, Suwon, Gyunggido, Republic of Korea
}

Received November 4, 2015; Accepted December 7, 2015

DOI: $10.3892 /$ ijo.2015.3303

\begin{abstract}
The aminoacyl-tRNA synthetase interacting multi-functional protein 1 (AIMP1) participates in a variety of cellular processes, including translation, cell proliferation, inflammation and wound healing. Previously, we showed that the N-terminal peptide of AIMP1 (6-46 aa) induced ERK phosphorylation. Liver fibrosis is characterized by excessive deposition of extracellular matrix, which is induced by TGF $\beta$ signaling, and activated ERK is known to induce the phosphorylation of SMAD, thereby inhibiting TGF $\beta$ signaling. We assessed whether the AIMP1 peptide can inhibit collagen synthesis in hepatic stellate cells (HSCs) by activating ERK. The AIMP1 peptide induced phosphorylation of SMAD2 via ERK activation, and inhibited the nuclear translocation of SMAD, resulting in a reduction of the synthesis of type I collagen. The AIMP1 peptide attenuated liver fibrosis induced by $\mathrm{CCl}_{4}$, in a dose-dependent manner. Masson-Trichrome staining showed that the AIMP1 peptide reduced collagen deposition. Immunohistochemical staining showed that the levels of $\alpha$-SMA, TGF $\beta$ and type I collagen were all reduced by the AIMP1 peptide. Liver toxicity analysis showed that the AIMP1 peptide improved the levels of relevant biological parameters in the blood. These results suggest that AIMP1 peptide may have potential for development as a therapeutic agent to treat liver fibrosis.
\end{abstract}

Correspondence to: Professor Soon-Sun Hong, Department of Biomedical Sciences, College of Medicine, Inha University, 3-ga, Sinheung-dong, Jung-gu, Incheon 400-712, Republic of Korea E-mail: hongs@inha.ac.kr

Professor Sang Gyu Park, Department of Pharmacy, College of Pharmacy, Ajou University, Suwon, Gyunggido, Republic of Korea E-mail: sgpark@ajou.ac.kr

${ }^{*}$ Contributed equally

Key words: aminoacyl-tRNA synthetase interacting multifunctional protein 1 , fibrosis, SMAD, TGF $\beta$

\section{Introduction}

Liver fibrosis may be considered a wound healing process induced in response to chronic liver injury resulting from a variety of insults including viruses, autoimmunity, drugs and metabolic diseases $(1,2)$. As a consequence of fibrosis, there may be distortion of the liver parenchyma because of nodule formation, and altered blood flow, which lead to cirrhosis and liver failure. Liver fibrosis is characterized by the accumulation of extracellular matrix (ECM) and hepatic stellate cells (HSCs) are responsible for most of the production and accumulation of collagen in injured liver although, bone marrow-derived fibrocytes as well as portal, and septal fibroblasts are also involved in this process $(3,4)$. Following liver injury, HSCs are activated, and transition from quiescent cells into proliferative, fibrogenic, and contractile myofibroblasts. This activation increases the expression of $\alpha$-smooth muscle actin ( $\alpha$-SMA), collagen and tissue inhibitors of metalloproteinases (TIMPs), giving rise to fibrotic liver (5). A variety of antifibrotic therapeutic strategies designed to reverse the damage, including suppression of HSC proliferation, or stimulation of apoptosis, downregulation of collagen between production and promotion of collagen degradation, as well as cell therapy using mesenchymal stem cells, have been tried (6-11).

TGF $\beta$ signaling has long been believed to be a central mediator of the fibrotic response (12). This signaling is mediated by regulatory SMADs (SMAD2 or SMAD3) which are phosphorylated by the activated TGF $\beta$ receptor complex and form heterodimers with SMAD4. The dimerization induces translocation of the SMAD complex to the nucleus where it exerts its regulatory function. As part of the development of the fibrotic liver, an increased expression of TGF $\beta$ recruits neutrophils, macrophages and fibroblasts, which exacerbate the liver fibrosis $(13,14)$. Recently, phosphorylation of SMAD2 $\left[\mathrm{Ser}^{245}, \mathrm{Ser}^{250}, \mathrm{Ser}^{255}\right.$ and $\left.\mathrm{Thr}^{220}(15)\right], \mathrm{SMAD} 3\left[\mathrm{Ser}^{203}, \mathrm{Ser}^{207}\right.$ and $\left.\mathrm{Thr}^{178}(16)\right]$, by growth factor-mediated ERK activation, has been shown to inhibit the TGF $\beta$-mediated nuclear translocation of the SMAD complex $(17,18)$. In addition, SMAD phosphorylation by Akt was shown to inhibit the nuclear 
translocation of SMAD, leading to a reduced expression of TGF $\beta$ target genes (19-21). Furthermore, it has been shown that FGF inhibits the synthesis of type I collagen, the major ECM component of the fibrotic tissue, at the level of transcription $(22,23)$.

AIMP1 is a cofactor of the multi-tRNA synthetase complex (24) that is induced by a variety of conditions including hypoxia, cytokines and hypoglycemia, and has agonistic or antagonistic effects on endothelial and immune cells (25-32). Recently, we reported that the 6-46 aa domain of secreted AIMP1 activated ERK and Akt via FGFR2, leading to the increased proliferation of mesenchymal stem cells (33). In the present study, we examined whether the AIMP1 peptide could inhibit collagen synthesis via ERK activation in TGF $\beta$-stimulated HSCs and attenuate liver fibrosis in a mouse model.

\section{Materials and methods}

Cell culture. LX2 cells, immortalized human HSCs, were kindly provided by Professor S.L. Friedman (Liver Disease Research Center of San Francisco General Hospital, San Francisco, CA, USA) and were maintained in high-glucose Dulbecco's modified Eagle's medium (DMEM) supplemented with $2 \%$ fetal bovine serum (FBS) and $1 \%$ streptomycin/ penicillin. For western blot analysis, LX2 cells were seeded at $\sim 70 \%$ confluence, on $60-\mathrm{mm}$ dishes $\left(2 \times 10^{5}\right.$ cells $)$ or $100-\mathrm{mm}$ dishes $\left(7 \times 10^{5}\right.$ cells) and cultured for $24 \mathrm{~h}$. After starvation for $12 \mathrm{~h}$ (reduction of FBS to $0.5 \%$ ), LX2 cells were treated with AIMP1 peptide as indicated. For the ERK inhibition assay, LX2 cells, starved for $12 \mathrm{~h}$ as above, were treated with AIMP1 peptide in the presence or absence of the selective inhibitor of MAP kinases, U0126 (10 $\mu \mathrm{M})$ for $30 \mathrm{~min}$, before TGF $\beta$ $(2 \mathrm{ng} / \mathrm{ml})$ was added.

Western blot analysis. For protein extraction, LX2 cells were washed with cold 1X PBS, and lysed on ice for $30 \mathrm{~min}$ in cold RIPA buffer (Sigma, $50 \mathrm{mM}$ HEPES, $150 \mathrm{mM} \mathrm{NaCl}, 1 \mathrm{mM}$ EDTA, $10 \%$ Glycerol, $1 \%$ Triton X-100, $0.1 \%$ SDS, $0.1 \%$ sodium deoxycholate, $12 \mathrm{mM} \beta$-glycerophosphate, $10 \mathrm{mM} \mathrm{NaF}, 1 \mathrm{mM}$ $\mathrm{NaOV}_{3}, 1 \mathrm{mM}$ PMSF, $2 \mathrm{mM} \beta$-mercaptoethanol) containing a protease inhibitor cocktail (Cell Signaling Technology), followed by centrifugation at $15,000 \mathrm{rpm}$ for $20 \mathrm{~min}$. The cells were fractionated into nucleus and cytoplasm using the anuclear/cytosol fractionation kit (BioVision) according to the manufacturer's instructions, and confirmed by western blot analysis using $\alpha$-tubulin and lamin $\mathrm{A} / \mathrm{C}$ for cytoplasm and nucleus, respectively. Approximately $20 \mu \mathrm{g}$ of total proteins was loaded and separated by SDS-polyacrylamide gel electrophoresis (PAGE). Proteins were transferred to polyvinylidene fluoride (PVDF) membranes using the wet transfer kit (BioRad Laboratories, Hercules, CA, USA), followed by blocking for 30 min with 5\% skim milk in Tris-buffered saline (TBS) with $0.1 \%$ Tween-20 (TBS-T), and then incubated overnight at $4^{\circ} \mathrm{C}$ in TBS containing 5\% skim milk with the indicated primary antibodies; anti-pSMAD2 (Ser465/467, 1:1,000; Cell Signaling Technology), anti-pSMAD3 (Ser423/425, 1:1,000; Cell Signaling Technology), anti-SMAD2/3 (1:1,000; Cell Signaling Technology), anti-SMAD4 (1:1,000; Santa Cruz Biotechnology), anti-collagen type I (1:1,000; Millipore), antiLamin A/C (1:1,000; Abcam) anti- $\alpha$-Tubulin (1:1,000; Sigma).
The membranes were then washed four times for $10 \mathrm{~min}$ in TBS-T solution and incubated with horseradish peroxidaseconjugated secondary antibodies $(0.1 \mu \mathrm{g} / \mathrm{ml}$; Santa Cruz Biotechnology). Immunoreactivity bands were detected using the western blot detection kit (Abc-3001; AbClon), according to the manufacturer's instructions.

Immunofluorescence. $\mathrm{LX} 2$ cells $\left(2 \times 10^{4}\right.$ cells) were cultured for $24 \mathrm{~h}$ on round glass coverslips (VWR LabShop, Batavia, IL, USA) in 24-well plates. After $0.5 \%$ FBS starvation for $12 \mathrm{~h}$, the cells were treated with $5 \mu \mathrm{g} / \mathrm{ml}$ of AIMP1 peptide for $30 \mathrm{~min}$, followed by $2 \mathrm{ng} / \mathrm{ml}$ of TGF $\beta$ for $1 \mathrm{~h}$. The cells were fixed with $4 \%$ formaldehyde freshly prepared from paraformaldehyde for $10 \mathrm{~min}$ and then permeabilized with PBS supplemented with $0.1 \%$ Triton X-100 (PBST) for 5 min. After washing with PBST three times for $5 \mathrm{~min}$, fixed cells were incubated for an additional 30 min in PBST containing 5\% BSA to prevent non-specific binding of the antibodies, followed by an overnight incubation at $4^{\circ} \mathrm{C}$ with the indicated primary antibodies. Cells were washed three times with PBST solution, and then incubated with Alexa 488 and 594-conjugated goat anti-mouse or anti-rabbit secondary antibodies (Molecular Probes) for $1 \mathrm{~h}$ at room temperature. Nuclear DNA was counterstained with 4',6'-diamidino-2-phenylindole (DAPI) and the fluorescence was captured with the Leica confocal microscope TCS SP5 (Leica Microsystems, Wetzlar, Germany).

Immunoprecipitation. After serum starvation for $4 \mathrm{~h}, \mathrm{LX} 2$ cells were treated with AIMP1 peptide $(5 \mu \mathrm{g} / \mathrm{ml})$ in the presence or absence of U0126 $(10 \mu \mathrm{M})$. Cells were harvested, lysed with RIPA buffer, and incubated on ice for $30 \mathrm{~min}$. Whole cell lysates were prepared by centrifugation at $25,000 \mathrm{x} \mathrm{g}$ for $10 \mathrm{~min}$ at $4^{\circ} \mathrm{C}$. The protein extracts $(300 \mu \mathrm{g})$ were incubated with anti-SMAD2/3 antibody (1.5 $\mu \mathrm{g}$; Cell Signaling Technology) for $4 \mathrm{~h}$ at $4^{\circ} \mathrm{C}$ and then with protein A agarose for $4 \mathrm{~h}$, also at $4^{\circ} \mathrm{C}$. The beads were washed three times with RIPA buffer without $\beta$-mercaptoethanol, and resuspended in $1 \mathrm{X}$ SDS sample buffer. The samples were boiled and loaded into 9\% SDS-PAGE. Phosphorylation of SMAD2/3 was confirmed by pSer antibody (Abcam).

Luciferase activity assay. LX2 cells $\left(5 \times 10^{4}\right.$ cells) were seeded on a 12-well plate and cultured in DMEM supplemented with $2 \%$ fetal bovine serum (FBS) and 1\% streptomycin/penicillin. The cells were then co-transfected with a SBE4-Luc vector containing the SMAD binding element (SBE) and Renilla luciferase vector using Lipofectamine 2000 (Invitrogen) for $12 \mathrm{~h}$. After serum starvation with $0.5 \%$ FBS for $4 \mathrm{~h}, \mathrm{LX} 2$ cells were treated with AIMP1 peptide for 10 min and then TGF $\beta$ was added for an additional $20 \mathrm{~h}$. Luciferase activity was determined using the Dual-Luciferase Reporter Assay system (Promega) and quantified using GloMax (Promega) according to the manufacturer's instructions. Luciferase activity was normalized to Renilla luciferase activity.

$R T-P C R$. Total RNA was extracted using an RNA isolation kit (iNtRON Biotechnology, Inc., Seoul, Korea) according to the manufacturer's instructions. cDNA was prepared by reverse transcription with $0.5 \mu \mathrm{g}$ of total RNA. Type I collagen mRNA (NM_000088.3) (forward, 5'-CCCCTGGAAAGAATGGAG 
ATG-3' and reverse, 5'-TCCAAACCACTGAAACCTCTG-3'); GAPDH (forward, 5'-CGAGATCCCTCCAAAATCAA-3' and reverse, 5'-TGTGGTCATGAGTCCTTCCA-3') were amplified by real-time PCR, which was performed with the AccuPower ${ }^{\circledR}$ GreenStar qPCR PreMix (SYBR-Green PreMix; Bioneer Corp., Daejeon, Korea) and StepOne Real-Time PCR system (Applied Biosystems). GAPDH was used as an endogenous control.

Animal study. Male BALB/c mice (6 weeks old, weighing 20-22 g) were obtained from Orient Bio. Animal Inc. (Seoul, Republic of Korea). Animal care and all experimental procedures were conducted in accordance with the approval and guidelines of the Inha Institutional Animal Care and Use Committee (Inha IACUC) of the Medical School of Inha University (approval ID: 111024-1). The animals were fed standard chow and tap water ad libitum, and were maintained with a 12-h dark/light cycle at $21^{\circ} \mathrm{C}$. Acute liver damage was induced by intraperitoneal injection of $40 \% \mathrm{CCl}_{4}$ in corn oil at a single dose of $(150 \mu \mathrm{l})$ twice a week for one month. Control animals were treated with the same volume of corn oil alone. Mice in the scrambled AIMP1 and AIMP1 peptide groups were treated twice-weekly with intraperitoneal injections for 2 weeks during the $\mathrm{CCl}_{4}$ administration. All mice were sacrificed by ether anesthesia after 4 weeks of treatment. The livers were excised and weighed and the specimens were immediately fixed in $10 \%$ neutral buffered formalin for histochemical studies. Blood samples for biochemical analyses were obtained by cardiac puncture.

Histopathology. Liver samples fixed in a $10 \%$ buffered formaldehyde solution were processed using a paraffin slice technique. Sections $\sim 4-\mu \mathrm{m}$ thick were stained with hematoxylin and eosin (H\&E) for routine histological examination. The sections were first stained with hematoxylin for $3 \mathrm{~min}$, washed, and then stained with $0.5 \%$ eosin for an additional $3 \mathrm{~min}$. For staining of liver fibrosis, the fixed liver tissue samples were stained with Masson's trichrome according to standard protocol. After an additional wash with water, the slides were sequentially dehydrated in 70,95 and 100\% ethanol and cleared in xylene. The degree of liver damage was examined in a blinded manner by a pathologist using a light microscope (Olympus).

Assessment of biochemical parameters. Serum TotalBilirubin, D-Bilirubin, aspartate transaminase (AST), and alanine transaminase (ALT) levels were measured at the Green Cross Reference Lab (Seoul, Republic of Korea).

Immunohistochemistry. Immunohistochemical staining was performed using formalin-fixed and deparaffinized tissue sections as previously described $(34,35)$. After blocking with normal goat serum (Vector Laboratories, Burlingame, CA, USA) for $1 \mathrm{~h}$, primary antibodies specific for TGF $\beta$, collagen I, and $\alpha$-SMA (Sigma-Aldrich) were used. After removing the unbound primary antibody, the sections were incubated with secondary antibody in $1.5 \%$ horse serum/PBS at room temperature for $1 \mathrm{~h}$. The sections were visualized by an avidin-biotin peroxidase complex solution using an $\mathrm{ABC}$ kit (Vector Laboratories). The sections were washed in
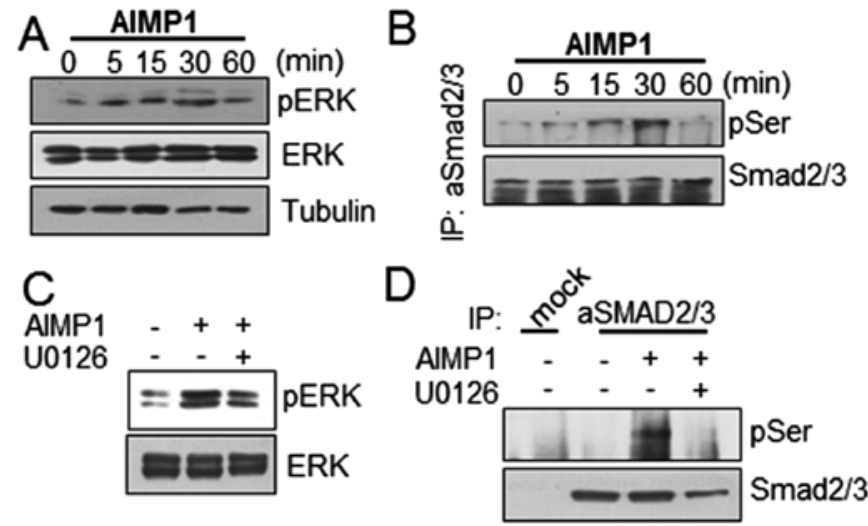

Figure 1. The AIMP1 peptide induces phosphorylation of SMAD via ERK activation. (A and B) LX2 cells were cultured in DMEM as described in Materials and methods. After serum starvation, AIMP1 peptide $(5 \mu \mathrm{g} / \mathrm{ml})$ was incubated with the cells, and then cell lysates were subjected to western blot analysis for the detection of pERK, ERK and Tubulin. Tubulin was used as a loading control. In addition, cell lysates $(300 \mu \mathrm{g})$ were subjected to immunoprecipitation using SMAD2/3 antibody and blotted with antiphospho-serine antibody. (C and D) LX2 cells were serum starved for $12 \mathrm{~h}$, and AIMP1 peptide was treated in the presence or absence of U0126 $(10 \mu \mathrm{M})$. Cell lysates were then subjected to SDS-PAGE for blotting and detection of pERK and ERK. In addition, cell lysates $(300 \mu \mathrm{g})$ were subjected to immunoprecipitation using SMAD2/3 antibody and blotted with anti-phospho-serine antibody as described above. These results were obtained from at least three independent experiments.

PBS, developed with a diaminobenzidine tetrahydrochloride substrate for $15 \mathrm{~min}$ and then the nucleus was counterstained with hematoxylin. Terminal deoxynucleotidyl transferasemediated nick end labelling (TUNEL) was performed using the TUNEL kit (Millipore, Billerica, MA, USA) according to the manufacturer's instructions.

Statistical analysis. Data are expressed as the mean $\pm \mathrm{SD}$, and analyzed with an ANOVA and unpaired Student's t-test. A P-value $\leq 0.05$ was considered to indicate a statistically significant result. Statistical calculations were performed using SPSS software for the Windows operating system (version 10.0; SPSS, Inc., Chicago, IL, USA).

\section{Results}

The AIMP1 peptide regulates SMAD2 localization via ERK activation. We have previously reported that the AIMP1 peptide activates MAPKs including ERK (33). In the present study, we used LX2 cells for human HSCs that were spontaneously immortalized in low serum condition, which express $\alpha$-smooth muscle actin, vimentin, glial fibrillary acid protein and other HSC biomarkers upon activation (36). We first examined whether the AIMP1 peptide could induce ERK phosphorylation in LX2 cells. AIMP1 peptide increased ERK phosphorylation in a time-dependent manner (Fig. 1A). Since the activation of ERK induces TGF $\beta$-independent phosphorylation of SMAD and inhibits nuclear translocation $(15,18,37)$, we examined whether AIMP1-mediated ERK phosphorylation induced SMAD2/3 phosphorylation. After treatment of LX2 cells with the AIMP1 peptide as indicated, cell lysates were prepared and the SMAD2/3 protein was immunoprecipitated using a specific antibody as described in Materials and 


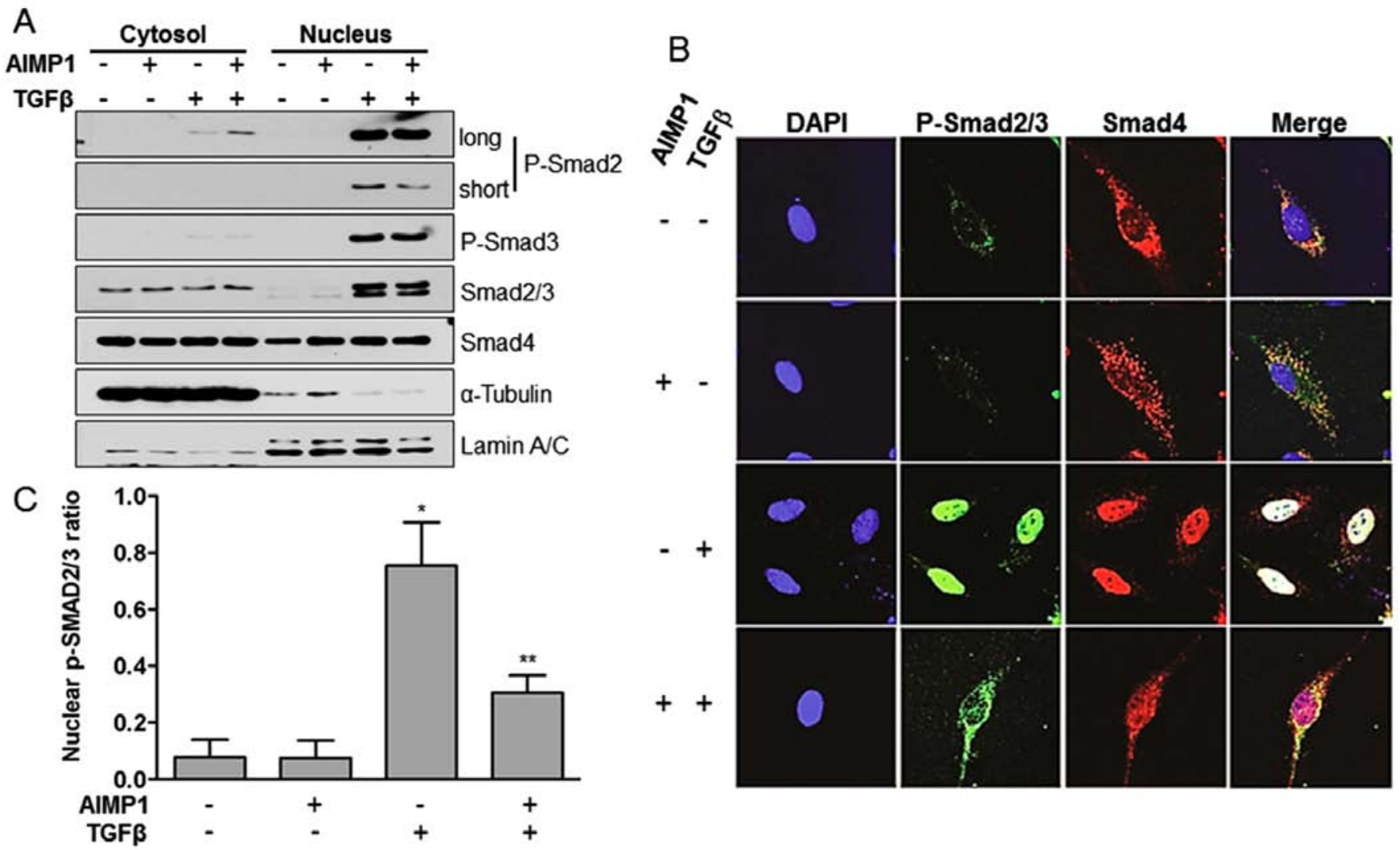

Figure 2. The AIMP1 peptide inhibits nuclear translocation of pSMAD2/3 induced by TGF $\beta$. (A and B) LX2 cells were serum starved for 4 h and AIMP1 peptide $(5 \mu \mathrm{g} / \mathrm{ml})$ was treated in the presence or absence of TGF $\beta(2 \mathrm{ng} / \mathrm{ml})$. Cells were fractionated into cytoplasm and nucleus, and then subjected to SDSPAGE for a western blot analysis of pSMAD, SMAD2/3, SMAD4, $\alpha$-Tubulin and Lamin A/C. $\alpha$-Tubulin was used as a cytoplasmic marker and Lamin A/C was used as a nuclear marker. Long and short stand for long and short exposure, respectively. (C) In addition, cells were fixed with $4 \%$ formaldehyde freshly prepared from paraformaldehyde and washed with PBS. Cells were incubated with pSMAD2/3 and SMAD4 antibodies as described in Materials and methods. The nucleus was counterstained with DAPI. Nuclear pSMAD2/3 was counted and evaluated. These results were obtained from at least three independent experiments. ${ }^{*} \mathrm{P}<0.01$, vs. TGF $\beta / \mathrm{AIMP}^{-} ;{ }^{* *} \mathrm{P}<0.01$, vs. TGF $\beta^{+} / \mathrm{AIMP} 1^{-}$

methods. The western blot analysis using anti-phospho-serine antibody, showed that the AIMP1 peptide induced phosphorylation of SMAD2 in a time-dependent manner (Fig. 1B). To verify whether the phosphorylation at the serine residue of SMAD2/3 was induced by AIMP1 peptide-mediated ERK phosphorylation, we treated the cells with U0126, an ERK inhibitor, and then analyzed the SMAD2/3 phosphorylation. The suppression of ERK phosphorylation by U0126 indeed reduced the AIMP1 peptide-mediated SMAD2 phosphorylation (Fig. 1C and D).

In order to transduce TGF $\beta$ signaling, the TGF $\beta$ receptor, activated by the ligand binding, phosphorylates SMAD2/3. The pSMAD2/3 then forms a complex with SMAD4, resulting in translocation to the nucleus, and regulation of a variety of TGF $\beta$ target genes including type I collagen (38). To investigate whether the AIMP1 peptide-mediated ERK activation could inhibit the TGF $\beta$-induced nuclear translocation of pSMAD2/3, we separated whole cell lysates into the cytoplasmic and nuclear fractions after treatment with AIMP1 peptide. Analysis of the separate fractions clearly showed that pre-treatment of LX2 cells with AIMP1 peptide reduced the nuclear translocation of pSMAD2, but not of pSMAD3 (Fig. 2A). We confirmed this result further by immunofluorescence staining. TGF $\beta$ stimulation of LX2 cells induced the nuclear translocation of pSMAD2/3 and SMAD4, whereas pretreatment with AIMP1 peptide inhibited the nuclear translocation of pSMAD2/3 (Fig. 2B and C). These results suggest that the AIMP1 peptide inhibits the nuclear translocation of pSMAD2/3 without affecting the phosphorylation of SMAD2/3 by TGF $\beta$.

The AIMP1 peptide inhibits the synthesis of type I collagen. TGF $\beta$ has been reported to induce the deposition of type I collagen at sites of injury in the liver, leading to liver fibrosis (39-41). Thus, we examined whether the reduction in the nuclear translocation of $\mathrm{pSMAD} 2 / 3$ seen after treatment with the AIMP1 peptide could inhibit the TGF $\beta$ mediated synthesis of type I collagen. Pretreatment with the AIMP1 peptide decreased type I collagen synthesis in a dose-dependent manner at the level of both mRNA and protein (Fig. 3A), suggesting that the decreased expression level of type I collagen was due to the reduced transcriptional activity of the SMAD complex in the nucleus. This is a result of the fact that the AIMP1 peptide inhibited the nuclear translocation of the pSMAD induced by TGF $\beta$. To further confirm the transcriptional activity of the SMAD complex, we carried out a luciferase activity assay using the SBE4-Luc vector containing SMAD binding element (SBE). The AIMP1 peptide attenuated the TGF $\beta$-mediated increase of luciferase activity in a dose-dependent manner 
A
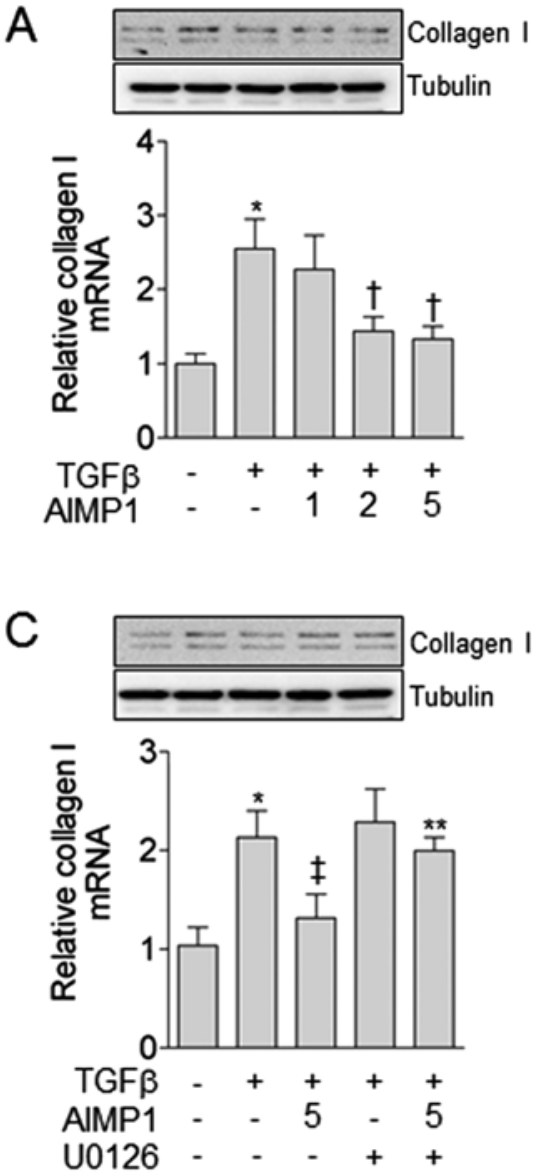

B

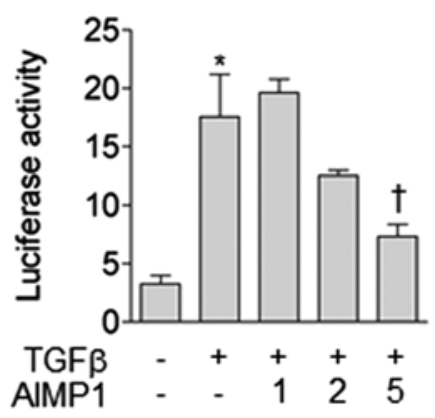

D

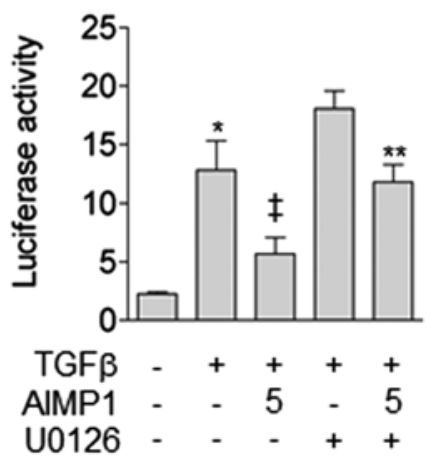

Figure 3. The AIMP1 peptide inhibits TGF 3 -mediated synthesis of type I collagen. (A and B) LX2 cells were treated with the AIMP1 peptide in a dosedependent manner in the presence of TGF $\beta(2 \mathrm{ng} / \mathrm{ml})$. The expression level of type I collagen was determined by western blot analysis and quantitative RT-PCR. Tubulin was used as a loading control. In addition, LX2 cells were then co-transfected with the SBE4-Luc vector containing the SMAD binding element (SBE) and the Renilla luciferase vector. The AIMP1 peptide was then incubated in the presence of TGF 3 ( $2 \mathrm{ng} / \mathrm{ml})$ for $24 \mathrm{~h}$ and luciferase activity was quantitated. "P<0.01, vs. TGF $\beta / A I M P 1 ;{ }^{\prime} \mathrm{P}<0.05$, vs. TGF $\beta^{+} / \mathrm{AIMP1}{ }^{-}$. (C and D) Cells were pre-treated with U0126 for 10 min and the AIMP1 peptide was added in the presence of TGF $\beta(2 \mathrm{ng} / \mathrm{ml})$ for an additional $24 \mathrm{~h}$. The expression of type I collagen was then determined by western blot analysis and quantitative RT-PCR. In addition, the transcriptional activity of SMAD was determined by co-transfection of the SBE4-Luc vector containing the SMAD binding element (SBE) and the Renilla luciferase vector. These results were obtained from at least three independent experiments ( $\mathrm{n}=4)$. ${ }^{*} \mathrm{P}<0.01, \mathrm{vs}$. TGF $\beta / \mathrm{AIMP1} / \mathrm{U} 0126$; ${ }^{\ddagger} \mathrm{P}<0.05$, vs. TGF $\beta^{+} / \mathrm{AIMP}^{-} / \mathrm{U} 0126 ;{ }^{* * *} \mathrm{P}<0.05$, vs. TGF ${ }^{+} / \mathrm{AIMP} 1(5) / \mathrm{U} 0126$.

(Fig. 3B). In addition, we investigated whether the AIMP1 peptide-mediated decrease of type I collagen expression was dependent on ERK activation. As shown in Fig. 3C, pre-treatment with U0126 abolished the AIMP1 peptidemediated reduction of type I collagen expression. The luciferase activity assay further confirmed that the AIMP1 peptide-mediated decrease of type I collagen expression is ERK-dependent (Fig. 3D).

The AIMP1 peptide decreases the severity of liver fibrosis in $\mathrm{CCl}_{4}$-induced mouse model. We next assessed whether the AIMP1 peptide could have a therapeutic effect in the $\mathrm{CCl}_{4}$ induced mouse model of liver, by inhibiting the expression of type I collagen induced by TGF $\beta$. The AIMP1 peptide was administered intraperitoneally twice weekly as described in Materials and methods. Histological analysis showed that treatment with the AIMP1 peptide decreased the $\mathrm{CCl}_{4}$ induced liver damage in a dose-dependent manner (Fig. 4A). In addition, Masson-Trichrome staining further clearly showed that collagen deposition was reduced by AIMP1 peptide treatment (Fig. 4A). The level of liver toxicity was examined by analysis of blood chemistry parameters. Treatment with the AIMP1 peptide significantly decreased the levels of total (T) and indirect (D) bilirubin, which were increased by $\mathrm{CCl}_{4}$. In addition, the AIMP1 peptide significantly decreased the levels of alanine aminotransferase (ALT) and aspartate aminotransferase (AST), suggesting that it could have a therapeutic effect on liver fibrosis in this model (Fig. 4B and C). To further confirm whether the therapeutic effect of the AIMP1 peptide is specific, we used scrambled AIMP1 peptide (sAIMP1) as a negative control, as previously described for a defective mutant Y24T (42). H\&E and Masson-Trichrome staining showed that the wild-type AIMP1 peptide significantly attenuated $\mathrm{CCl}_{4}$-induced liver fibrosis, whereas the sAIMP1 peptide did not, thereby confirming the specificity of the therapeutic effect (Fig. 4D and E). In addition, immunohistochemical staining clearly showed that the AIMP1, but not the sAIMP1, peptide reduced the levels of expression of $\alpha$-SMA, TGF $\beta$ and collagen (Fig. 4D and E). Furthermore, the AIMP1 peptide decreased hepatic apoptosis induced by $\mathrm{CCl}_{4}$ as measured by TUNEL (Fig. $4 \mathrm{D}$ and E). Serum markers for liver fibrosis including AST, ALT, albumin and BUN 
A

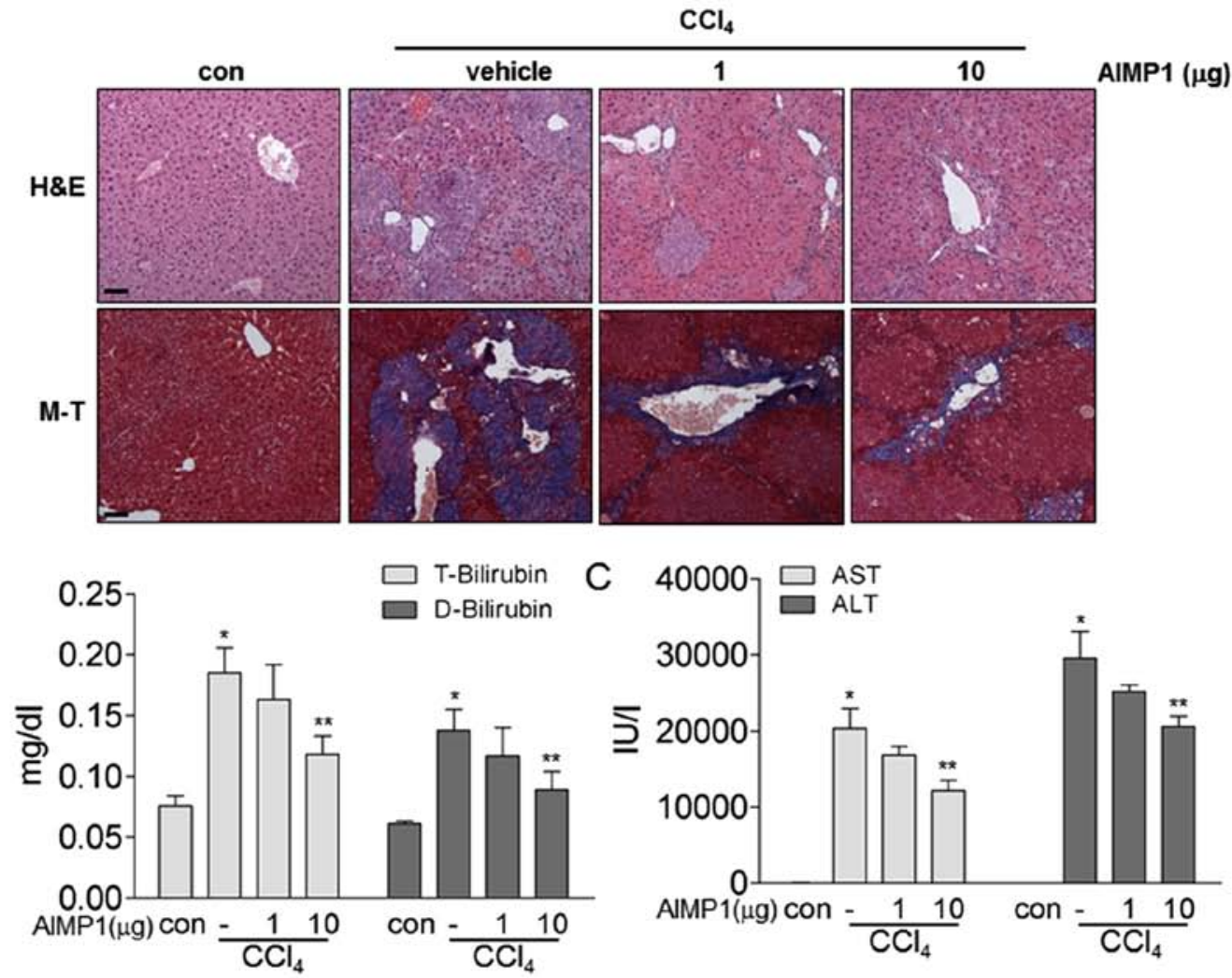

B

D

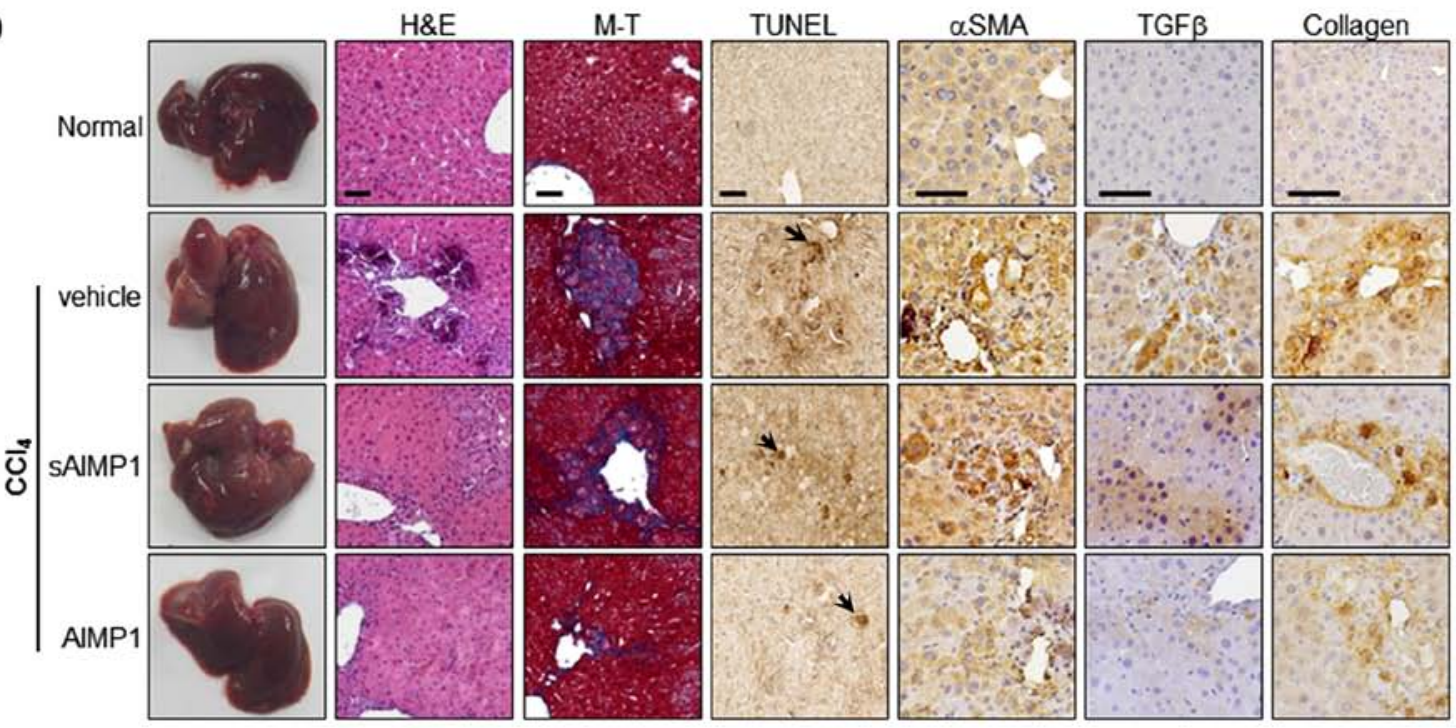

E
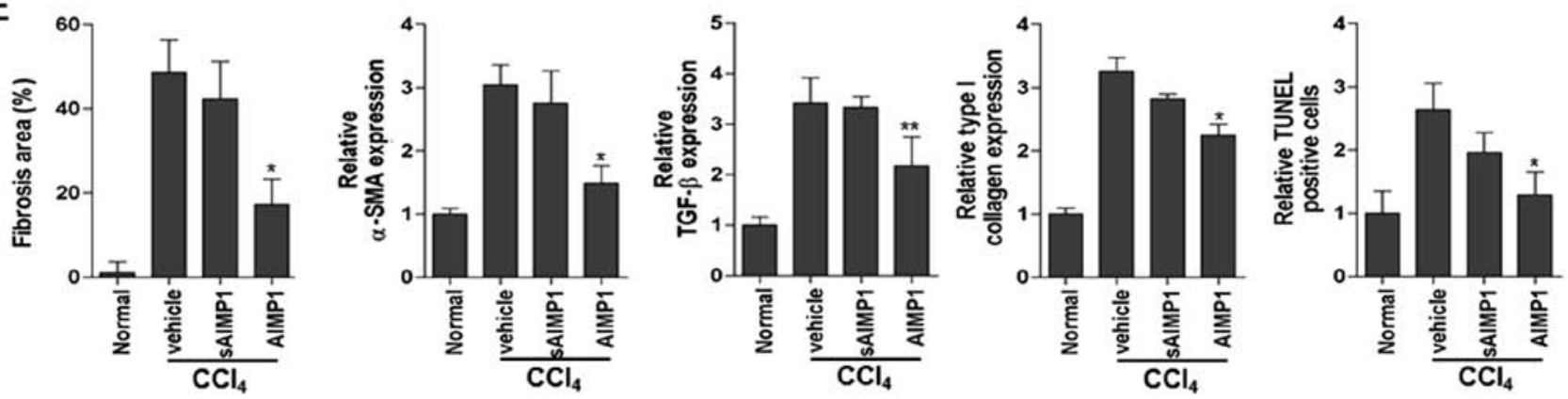

Figure 4. The AIMP1 peptide attenuates $\mathrm{CCl}_{4}$ - induced liver fibrosis. The AIMP1 peptide was administered intraperitoneally twice weekly to mice with $\mathrm{CCl}_{4}$ induced liver fibrosis (each group, $\mathrm{n}=5$ ). (A) Histological analysis was by H\&E and Masson-Trichrome staining (magnification, x200). (B and C) In addition, T-Bilirubin, D-Bilirubin, AST and ALT levels were quantified using blood. " $\mathrm{P}<0.01$ vs. con; ${ }^{* * *} \mathrm{P}<0.05$, vs. AIMP1 $/ \mathrm{CCl}_{4}$. (D and E) Vehicle, sAIMP1 peptide $(10 \mu \mathrm{g})$ or AIMP1 peptide $(10 \mu \mathrm{g})$ was administered as described above. Histological analyses [H\&E and Masson-Trichrome staining (magnification, x200)] and immunohistochemical analysis [ $\alpha$-SMA, TGF $\beta$, collagen and TUNEL (magnification, $\mathrm{x} 400$ )] were carried out and evaluated. Apoptotic cells are indicated by an arrow. Scale bar, $50 \mu \mathrm{m}$. 
Table I. Effect of AIMP1 on serum parameters in liver fibrosis.

\begin{tabular}{|c|c|c|c|c|}
\hline & \multirow[b]{2}{*}{ Control } & \multicolumn{3}{|c|}{$\mathrm{CCl}_{4}$} \\
\hline & & Vehicle & sAIMP1 & AIMP1 \\
\hline AST & $155.50 \pm 23.46$ & $232.17 \pm 21.60^{\mathrm{a}}$ & $195.20 \pm 17.68$ & $169.33 \pm 26.91^{\mathrm{c}}$ \\
\hline ALT & $57.83 \pm 5.81$ & $135.00 \pm 12.07^{b}$ & $123.60 \pm 19.17$ & $102.00 \pm 9.16^{\mathrm{c}}$ \\
\hline Albumin & $2.34 \pm 0.33$ & $1.66 \pm 0.03^{\mathrm{a}}$ & $2.06 \pm 0.26$ & $2.60 \pm 0.26^{\mathrm{d}}$ \\
\hline BUN & $38.00 \pm 4.82$ & $56.53 \pm 10.95^{\mathrm{a}}$ & $56.90 \pm 4.47$ & $28.82 \pm 11.5^{\mathrm{c}}$ \\
\hline
\end{tabular}

Control vs. $\mathrm{CCl}_{4},{ }^{\mathrm{a}} \mathrm{P}<0.05 ;{ }^{\mathrm{b}} \mathrm{P}<0.01 ; \mathrm{CCl}_{4}$ vs. AIMP $1,{ }^{\mathrm{c}} \mathrm{P}<0.05 ;{ }^{\mathrm{d}} \mathrm{P}<0.01$.

showed that the AIMP1 peptide significantly improved liver fibrosis, while the sAIMP1 peptide had no effect (Table I). In conclusion, these results suggest that the AIMP1 peptide attenuates liver fibrosis by inhibiting apoptosis induced by $\mathrm{CCl}_{4}$, which, in turn, leads to decreased collagen deposition, $\alpha$-SMA activation and TGF $\beta$ accumulation.

\section{Discussion}

Cytokines from a number of sources, including inflammatory cells, injured hepatocytes, and Kupffer cells (43), can activate quiescent HSCs and transform them into critical players in the exacerbation of liver fibrosis. In addition, HSCs, together with Kupffer cells and platelets represent the major reservoir of TGF $\beta$, a factor, which also plays an important role in the induction of liver fibrosis and cirrhosis (44-46) by inducing the excessive deposition of ECM including type I collagen. Furthermore, phosphorylation of SMAD by activated ERK inhibits SMAD activity by suppression of nuclear translocation $(15,18,37)$. In the present study, we examined whether the AIMP1 peptide, an activator of ERK, could inhibit TGF $\beta$ signaling by suppression of the nuclear translocation of SMADs and thereby inhibit the synthesis of type I collagen.

The AIMP1 peptide induced the phosphorylation of ERK in a time-dependent manner, and this lead to phosphorylation of the serine residue of SMAD2/3. Notably, western blot analysis after immunoprecipitation with SMAD2/3 antibody showed only the phosphor-serine of SMAD2, which suggests that only the SMAD2 molecule in the SMAD2/3 is phosphorylated by activated ERK (Fig. 1). Separate analysis of nuclear and cytoplasmic fractions clearly showed that the AIMP1 peptide inhibits the TGF $\beta$-mediated nuclear translocation of SMAD2, but not of SMAD3 (Fig. 2A). Further investigation will be needed to determine the reason for the selective phosphorylation of SMAD2 alone. The observation that SMAD2 phosphorylation by activated ERK inhibits nuclear translocation is in accordance with previous reports $(15,18,37)$. We also investigated whether the SMAD phosphorylation by the AIMP1 peptide-mediated ERK activation could affect the SMAD phosphorylation (SMAD2, Ser ${ }^{465 / 467}$; SMAD3, $\mathrm{Ser}^{423 / 425}$ ) by TGF $\beta$. However, the results showed no effect on the phosphorylation of SMAD2/3 by TGF $\beta$ (data not shown), which suggests that the AIMP1 peptide decreases the nuclear translocation by acting downstream of the TGF $\beta$-mediated phosphorylation of SMAD.
The entrance of the phosphorylated SMAD complex into the nucleus results in an increase in the levels of expression of type I collagen. Since the nuclear translocation of SMAD complex is decreased by the AIMP1 peptide-mediated ERK activation we examined whether treatment with the AIMP1 peptide could also decrease the type I collagen synthesis in HSCs. Western blot analysis showed that the AIMP1 peptide decreased the level of type I collagen expression in a dosedependent manner. In addition, qRT-PCR and the luciferase activity assay confirmed that this decrease is regulated at the level of transcription level (Fig. 3).

The fact that treatment with the AIMP1 peptide reduced the level of expression of type I collagen in HSCs, suggests that this peptide may be applicable to treat liver fibrosis in vivo. We first examined whether the AIMP1 peptide was cytotoxic for hepatocytes. A cytotoxicity assay using HepG2 cells in vitro did not show any evidence for cytotoxicity of the AIMP1 peptide at concentrations up to $100 \mu \mathrm{g} / \mathrm{ml}$ (data not shown). To assess the in vivo efficacy of the AIMP1 peptide, we generated a liver fibrosis model using $\mathrm{CCl}_{4}$ and found that the AIMP1 peptide significantly attenuates both histopathological and biomarker parameters for liver fibrosis in the mice (Fig. 4A-C). To assess the specificity of the AIMP1 peptide effect, we used an SAIMP1 peptide as a negative control since the Y24T mutation of the AIMP1 peptide was previously shown to lack biological activity on fibroblasts (42). H\&E and MT staining showed that the AIMP1 peptide attenuated liver fibrosis compared to the vehicle and the SAIMP1 peptide (Fig. 4D and E). Immunohistochemical staining of $\alpha$-SMA, TGF $\beta$, and collagen and fibrogenic markers also showed that the AIMP1 peptide clearly attenuated $\mathrm{CCl}_{4}$-induced liver fibrosis. In the fibrotic liver, damaged tissues undergo apoptosis and release metabolites into the blood. An assay for apoptosis using TUNEL immunohistochemical staining showed that the AIMP1 peptide decreased apoptosis in the liver tissue. In addition, analysis of liver fibrosis biomarkers in the serum clearly showed that treatment with the AIMP1 peptide improved the levels of the relevant parameters (Table I).

In conclusion, the AIMP1 peptide inhibited the nuclear translocation of the SMAD complex, resulting in a reduced level of expression of type I collagen, and thereby efficiently inhibited the development of liver fibrosis in a $\mathrm{CCl}_{4}$-induced mouse model. We therefore suggest that the AIMP1 peptide might be useful to treat liver fibrosis as an inhibitor of TGF $\beta$ signaling and should be investigated further. 


\section{Acknowledgements}

The present study was supported by the Bio and Medical Technology Development Program [NRF-2012M3A9C6049719 (to S.G.P.)], the Bio-Synergy Research Project (NRF2015M3A9C4075818), and the Medical Research Center (2014009392, MSIP) through the National Research Foundation, Korea (to S.S.H).

\section{References}

1. Friedman SL: Mechanisms of hepatic fibrogenesis Gastroenterology 134: 1655-1669, 2008.

2. Li JT, Liao ZX, Ping J, Xu D and Wang H: Molecular mechanism of hepatic stellate cell activation and antifibrotic therapeutic strategies. J Gastroenterol 43: 419-428, 2008

3. Russo FP, Alison MR, Bigger BW, Amofah E, Florou A, Amin F, Bou-Gharios G, Jeffery R, Iredale JP and Forbes SJ The bone marrow functionally contributes to liver fibrosis Gastroenterology 130: 1807-1821, 2006.

4. Pinzani M and Rombouts K: Liver fibrosis: From the bench to clinical targets. Dig Liver Dis 36: 231-242, 2004.

5. Iredale JP, Benyon RC, Arthur MJ, Ferris WF, Alcolado R, Winwood PJ, Clark N and Murphy G: Tissue inhibitor of metalloproteinase-1 messenger RNA expression is enhanced relative to interstitial collagenase messenger RNA in experimental liver injury and fibrosis. Hepatology 24: 176-184, 1996.

6. Cheng JH, She H, Han YP, Wang J, Xiong S, Asahina K and Tsukamoto H: Wnt antagonism inhibits hepatic stellate cell activation and liver fibrosis. Am J Physiol Gastrointest Liver Physiol 294: G39-G49, 2008.

7. Yoshiji H, Noguchi R, Kuriyama S, Ikenaka Y, Yoshii J, Yanase K, Namisaki T, Kitade M, Masaki T and Fukui H: Imatinib mesylate (STI-571) attenuates liver fibrosis development in rats. Am J Physiol Gastrointest Liver Physiol 288: G907-G913, 2005.

8. Son MK, Ryu YL, Jung KH, Lee H, Lee HS, Yan HH, Park HJ, Ryu JK, Suh JK, Hong S, et al: HS-173, a novel PI3K inhibitor, attenuates the activation of hepatic stellate cells in liver fibrosis. Sci Rep 3: 3470, 2013.

9. Bueno M, Salgado S, Beas-Zárate C and Armendariz-Borunda J: Urokinase-type plasminogen activator gene therapy in liver cirrhosis is mediated by collagens gene expression down-regulation and up-regulation of MMPs, HGF and VEGF. J Gene Med 8: 1291-1299, 2006.

10. Anselmi K, Stolz DB, Nalesnik M, Watkins SC, Kamath R and Gandhi CR: Gliotoxin causes apoptosis and necrosis of rat Kupffer cells in vitro and in vivo in the absence of oxidative stress: Exacerbation by caspase and serine protease inhibition. J Hepatol 47: 103-113, 2007.

11. Shackel N and Rockey D: In pursuit of the 'Holy Grail' - stem cells, hepatic injury, fibrogenesis and repair. Hepatology 41: $16-18,2005$.

12. LeRoy EC, Trojanowska MI and Smith EA: Cytokines and human fibrosis. Eur Cytokine Netw 1: 215-219, 1990.

13. Kane CJ, Hebda PA, Mansbridge JN and Hanawalt PC: Direct evidence for spatial and temporal regulation of transforming growth factor beta 1 expression during cutaneous wound healing. J Cell Physiol 148: 157-173, 1991.

14. Wahl SM, Hunt DA, Wakefield LM, McCartney-Francis N, Wahl LM, Roberts AB and Sporn MB: Transforming growth factor type beta induces monocyte chemotaxis and growth factor production. Proc Natl Acad Sci USA 84: 5788-5792, 1987.

15. Funaba M, Zimmerman CM and Mathews LS: Modulation of Smad2-mediated signaling by extracellular signal-regulated kinase. J Biol Chem 277: 41361-41368, 2002.

16. Matsuura I, Wang G, He D and Liu F: Identification and characterization of ERK MAP kinase phosphorylation sites in Smad3. Biochemistry 44: 12546-12553, 2005.

17. Mulder KM: Role of Ras and Mapks in TGFbeta signaling. Cytokine Growth Factor Rev 11: 23-35, 2000.

18. Kretzschmar M, Doody J, Timokhina I and Massagué J: A mechanism of repression of TGFbeta/Smad signaling by oncogenic Ras. Genes Dev 13: 804-816, 1999.
19. Conery AR, Cao Y, Thompson EA, Townsend CM Jr, Ko TC and Luo K: Akt interacts directly with $\mathrm{Smad} 3$ to regulate the sensitivity to TGF-beta induced apoptosis. Nat Cell Biol 6: 366-372, 2004.

20. Song K, Wang H, Krebs TL and Danielpour D: Novel roles of Akt and mTOR in suppressing TGF-beta/ALK5-mediated Smad3 activation. EMBO J 25: 58-69, 2006.

21. Remy I, Montmarquette A and Michnick SW: PKB/Akt modulates TGF-beta signalling through a direct interaction with Smad3. Nat Cell Biol 6: 358-365, 2004.

22. Takayama S, Murakami S, Miki Y, Ikezawa K, Tasaka S, Terashima A, Asano T and Okada H: Effects of basic fibroblast growth factor on human periodontal ligament cells. J Periodontal Res 32: 667-675, 1997.

23. Silverio-Ruiz KG, Martinez AE, Garlet GP, Barbosa CF, Silva JS, Cicarelli RM, Valentini SR, Abi-Rached RS and Junior CR: Opposite effects of bFGF and TGF-beta on collagen metabolism by human periodontal ligament fibroblasts. Cytokine 39: 130-137, 2007.

24. Quevillon S, Agou F, Robinson JC and Mirande M: The p43 component of the mammalian multi-synthetase complex is likely to be the precursor of the endothelial monocyte-activating polypeptide II cytokine. J Biol Chem 272: 32573-32579, 1997.

25. Matschurat S, Knies UE, Person V, Fink L, Stoelcker B, Ebenebe C, Behrensdorf HA, Schaper J and Clauss M: Regulation of EMAP II by hypoxia. Am J Pathol 162: 93-103, 2003.

26. Park SG, Shin H, Shin YK, Lee Y, Choi EC, Park BJ and Kim S: The novel cytokine p43 stimulates dermal fibroblast proliferation and wound repair. Am J Pathol 166: 387-398, 2005.

27. Park SG, Kang YS, Kim JY, Lee CS, Ko YG, Lee WJ, Lee KU, Yeom YI and Kim S: Hormonal activity of AIMP1/p43 for glucose homeostasis. Proc Natl Acad Sci USA 103: 1491314918, 2006.

28. Ko YG, Park H, Kim T, Lee JW, Park SG, Seol W, Kim JE, Lee WH, Kim SH, Park JE, et al: A cofactor of tRNA synthetase, $\mathrm{p} 43$, is secreted to up-regulate proinflammatory genes. $\mathrm{J}$ Biol Chem 276: 23028-23033, 2001.

29. Park SG, Kang YS, Ahn YH, Lee SH, Kim KR, Kim KW, Koh GY, Ko YG and Kim S: Dose-dependent biphasic activity of tRNA synthetase-associating factor, p43, in angiogenesis. J Biol Chem 277: 45243-45248, 2002.

30. Park H, Park SG, Lee JW, Kim T, Kim G, Ko YG and Kim S: Monocyte cell adhesion induced by a human aminoacyl-tRNA synthetase-associated factor, p43: Identification of the related adhesion molecules and signal pathways. J Leukoc Biol 71: 223-230, 2002.

31. Kim E, Kim SH, Kim S and Kim TS: The novel cytokine p43 induces IL-12 production in macrophages via NF-kappaB activation, leading to enhanced IFN-gamma production in $\mathrm{CD}^{+} \mathrm{T}$ cells. J Immunol 176: 256-264, 2006.

32. Kim E, Kim SH, Kim S, Cho D and Kim TS: AIMP1/p43 protein induces the maturation of bone marrow-derived dendritic cells with $\mathrm{T}$ helper type 1-polarizing ability. J Immunol 180: 2894-2902, 2008.

33. Kim SY, Son WS, Park MC, Kim CM, Cha BH, Yoon KJ, Lee SH and Park SG: ARS-interacting multi-functional protein 1 induces proliferation of human bone marrow-derived mesenchymal stem cells by accumulation of $\beta$-catenin via fibroblast growth factor receptor 2-mediated activation of Akt. Stem Cells Dev 22: 2630-2640, 2013.

34. Lee JH, Lee H, Joung YK, Jung KH, Choi JH, Lee DH, Park KD and Hong SS: The use of low molecular weight heparinpluronic nanogels to impede liver fibrosis by inhibition the TGF- $\beta$ /Smad signaling pathway. Biomaterials 32: 1438-1445, 2011.

35. Coffer PJ, Jin J and Woodgett JR: Protein kinase B (c-Akt): A multifunctional mediator of phosphatidylinositol 3-kinase activation. Biochem J 335: 1-13, 1998.

36. Xu L, Hui AY, Albanis E, Arthur MJ, O'Byrne SM, Blaner WS, Mukherjee P, Friedman SL and Eng FJ: Human hepatic stellate cell lines, LX-1 and LX-2: New tools for analysis of hepatic fibrosis. Gut 54: 142-151, 2005.

37. Kretzschmar M, Doody J and Massagué J: Opposing BMP and EGF signalling pathways converge on the TGF-beta family mediator Smad1. Nature 389: 618-622, 1997. 
38. Chen SJ, Yuan W, Mori Y, Levenson A, Trojanowska M and Varga J: Stimulation of type I collagen transcription in human skin fibroblasts by TGF-beta: Involvement of Smad 3. J Invest Dermatol 112: 49-57, 1999.

39. Qi Z, Atsuchi N, Ooshima A, Takeshita A and Ueno H: Blockade of type beta transforming growth factor signaling prevents liver fibrosis and dysfunction in the rat. Proc Natl Acad Sci USA 96: 2345-2349, 1999.

40. Bataller R and Brenner DA: Liver fibrosis. J Clin Invest 115 209-218, 2005.

41. Wynn TA: Common and unique mechanisms regulate fibrosis in various fibroproliferative diseases. J Clin Invest 117: 524-529, 2007.

42. Han JM, Park SG, Lee Y and Kim S: Structural separation of different extracellular activities in aminoacyl-tRNA synthetaseinteracting multi-functional protein, p43/AIMP1. Biochem Biophys Res Commun 342: 113-118, 2006.
43. Friedman SL: Molecular regulation of hepatic fibrosis, an integrated cellular response to tissue injury. J Biol Chem 275: 2247-2250, 2000.

44. Gressner AM: Cytokines and cellular crosstalk involved in the activation of fat-storing cells. J Hepatol 22 (Suppl): 28-36, 1995.

45. Bissell DM, Wang SS, Jarnagin WR and Roll FJ: Cell-specific expression of transforming growth factor-beta in rat liver. Evidence for autocrine regulation of hepatocyte proliferation. J Clin Invest 96: 447-455, 1995.

46. Chen A and Davis BH: The DNA binding protein BTEB mediates acetaldehyde-induced, jun N-terminal kinase-dependent alphaI(I) collagen gene expression in rat hepatic stellate cells. Mol Cell Biol 20: 2818-2826, 2000 